\title{
Pelatihan Culinary Entrepreneur Dalam Mengembangkan Kinerja UMKM di Masa Pandemi
}

\author{
Yuliana Riana Prasetyawati ${ }^{1}$, Emilya Setyaningtyas $^{2}$, Jati Paras $\mathrm{Ayu}^{3}$ \\ Kartini Dwi Sartika ${ }^{4}$ dan Sandy Adithia ${ }^{5}$ \\ 1,2,3,4,5 Institut Komunikasi dan Bisnis LSPR, Jakarta, Indonesia
}

\begin{abstract}
ABSTRAK
Pada masa pandemi Covid-19, UMKM Kuliner merupakan salah satu UMKM yang terkena dampak paling signifikan. Hal ini karena UMKM memiliki ketahanan dan fleksibilitas yang rendah dalam menghadapi pandemi ini. Salah satu strategi yang dapat dilakukan untuk meningkatkan kinerja penjualan adalah memanfaatkan digital marketing. Namun UMKM masih memiliki tingkat digitalisasi yang masih rendah. Oleh karena itu, kegiatan pelatihan ini ditujukan bagi UMKM Kuliner yang berada di wilayah Jabodetabek agar lebih memahami peran public relation dan penggunaan media sosial sebagai strategi komunikasi pemasaran agar mampu bertahan di masa pandemi ini. Pelatihan ini dilakukan melalui media online dan dilanjutkan dengan penilaian pada proposal bisnis yang diajukan oleh pelaku UMKM Kuliner. Kegiatan LSPR Culinary Entrepreneur ini berjalan dengan lancar dan para peserta dapat meningkatkan pengetahuan dan ketrampilan penggunaan digital marketing dan public relation sebagai strategi pemasaran UMKM untuk bertahan di masa pandemi Covid- 19.
\end{abstract}

Kata kunci: UMKM kuliner; digital marketing; pandemi Covid-19

\begin{abstract}
During the Covid-19 pandemic, Culinary MSMEs were one of the MSMEs that were most significantly affected. This is because MSMEs have low resilience and flexibility in dealing with this pandemic. One strategy that can be done to improve sales performance is to utilize digital marketing. However, MSMEs still have a low level of digitization. Therefore, this training activity is intended for Culinary MSMEs in the Jabodetabek area to better understand the role of public relations and the use of social media as a marketing communication strategy to survive this pandemic. This training is carried out through online media and is followed by an assessment of business proposals submitted by Culinary MSME actors. The LSPR Culinary Entrepreneur activity went smoothly and the participants were able to improve their knowledge and skills in using digital marketing and public relations as a marketing strategy for MSMEs to survive the Covid-19 pandemic.
\end{abstract}

Keywords: kulinary MSMEs, digital marketing, the Covid-19 pandemic

\section{PENDAHULUAN}

Usaha Mikro Kecil dan Menengah (UMKM) merupakan tulang punggung perekonomian Indonesia. Menurut UU No. 20/2008, UMKM adalah per dan sektor UMKM ini telah menyerap tenaga kerja sebesar $97 \%$ di Indonesia. Namun, pandemi Covid-19, telah menurunkan kinerja 
UMKM. Menurut data Kementerian Koperasi dan UKM tercatat sejumlah 67.051 UMKM yang terkena terdampak pandemi Covid-19 di Indonesia dan salah satu jenis usaha yang paling terkena dampak pandemi ini adalah usaha penyediaan akomodasi makan dan minuman.

UMKM kurang memiliki ketahanan dan fleksibilitas dalam menghadapi pandemi ini dikarenakan beberapa hal seperti tingkat digitalisasi yang masih rendah, kesulitan dalam mengakses teknologi dan kurangnya pemahaman tentang strategi bertahan dalam bisnis (Hardilawati, 2020). Karakteristik UMKM yang memiliki sistem pembukuan yang sederhana, profit yang relatif kecil, dan keterbatasan promosi (Anoraga dalam Rosita (2020), membuat kemampuan bertahan di pandemi ini relatif tidak lama.

Meningkatnya jumlah masyarakat yang terkena Covid-19, membuat pemerintah mengeluarkan PP Nomor 21 tahun 2020 tentang Pembatasan Sosial Berskala Besar (PSBB) yang membatasi pergerakan masyarakat untuk beraktivitas diluar rumah. Masyarakat memilih memasak dan menikmati makanan bersama keluarga di rumah. Hal ini tentu saja berdampak pada UMKM Kuliner dengan berkurangnya konsumen yang membeli produk kuliner. Faktor lain, adalah meningkatnya harga bahan baku. Selama masa pandemi ini, UMKM relatif sulit mendapatkan bahan baku (Catriana, 2020).

Beberapa cara dapat dilakukan oleh UMKM Kuliner untuk mampu bertahan dalam kondisi pandemi ini. UMKM dapat mengomunikasikan produk kuliner secara intensif melalui digital marketing. UMKM memanfaatkan media sosial untuk dapat menjangkau konsumennya secara langsung dan dapat menekan biaya promosi. Hasil penelitian (Hendrawan et al., 2019) menyatakan bahwa digital marketing berpengaruh positif dan signifikan terhadap peningkatan penjualan UMKM. Selain itu, UMKM dapat memanfaatkan media sosial dan e commerce sebagai tempat jual beli produk kuliner selama pandemi ini. Namun demikian, transformasi digitalisasi pada UMKM relatif masih baru. UMKM belum dapat melakukan adopsi digital secara baik dalam elemen pemasaran. Oleh karena itu, Institut Komunikasi dan Bisnis LSPR sebagai institusi pendidikan terpanggil memberikan dukungan dan kontribusi dalam bentuk pelatihan bagi UMKM Kuliner agar struktur UMKM menjadi kuat dan mampu bertahan di masa pandemi ini.

\section{METODOLOGI PELAKSANAAN}

Pelatihan LSPR Culinary Entrepreneur ini merupakan program pengabdian kepada masyarakat yang dilakukan secara berkelompok dan lintas prodi dari dosen Fakultas Komunikasi dan dosen Fakultas Bisnis. LSPR Culinary Entrepreneur dilaksanakan pada 2021 diikuti oleh 44 UMKM kuliner di yang berada di Jakarta dan Bekasi. Produk kuliner dari para UMKM ini beragam, mulai dari makanan pembuka (appetizer), makanan utama (main course), minuman (beverages) dan makanan penutup (dessert). Pelatihan LSPR Culinary Entrepreneur ini merupakan rangkaian dari program LSPR Culinary Entrepreneur Award 2021 yang diadakan 
oleh Fakultas Bisnis, Institut Komunikasi dan Bisnis LSPR bersama LSPR Plaza yang merupakan pasar virtual non-transaksional yang menyediakan beragam produk mulai dari kuliner dan fashion. Program LSPR Culinary Entrepreneur Award 2021 diadakan pada Januari - Maret 2021 yang salah satu tujuannya adalah sebagai wadah bagi UMKM Kuliner untuk dapat mengembangkan usaha bisnisnya melalui pelatihan yang dilakukan oleh pengusaha yang sukses dan praktisi dibidangnya.

Berdasarkan hasil survei yang dilakukan, para pemilik UMKM kuliner ini dominan membutuhkan pelatihan untuk lebih memahami peran public relation dan penggunaan media sosial sebagai strategi komunikasi pemasaran. Kegiatan pelatihan ini dilakukan dalam tiga sesi, yaitu sesi pertama membahas mengenai Public Relation for Entrepreneur yang menjelaskan tentang sesi kedua membahas mengenai 'How Culinary Business Can Survive During Pandemic', dan sesi ketiga membahas terkait 'The Role of Social Media for Branding' yang memaparkan peran penting dan tantangan penggunaan media sosial sebagai strategi pemasaran. Diskusi dan tanya jawab dilakukan disetiap sesi setelah pemaparan oleh pemateri.

Pelaksanaan pelatihan dilakukan secara online melalui media Zoom pada 19 Februari 2021. Selanjutnya proposal UMKM Kuliner ini dievaluasi oleh tim dewan juri yang terdiri dari pengusaha sukses, praktisi dan akademisi dibidang pemasaran. Proposal dinilai berdasarkan lima kriteria yaitu inovasi produk kuliner, desain kemasan atau cara menyajikan makanan, strategi pemasaran, implemetasi taktik pemasaran dan motivasi berwirausaha. Dewan juri melakukan penilaian secara desk evaluation dan mengadakan rapat pada 27 Februari 2021 untuk menentukan sepuluh finalis LSPR Culinary Entrepreneur Award 2021. Pada 5 Maret 2021, sepuluh finalis melakukan presentasi didepan dewan juri dan panitia LSPR Culinary Entrepreneur Award 2021.

\section{HASIL DAN PEMBAHASAN}

Kegiatan Pelatihan LSPR Culinary Entrepreneur ini, diawali dengan pemaparan materi mengenai 'How Culinary Business Can Survive During Pandemic' yang disampaikan oleh Founder OK Oce Indonesia yaitu Bapak Indra Uno. Pemateri terlebih dahulu menyampaikan mengenai pola pikir wirausaha untuk meningkatkan motivasi wirausaha bagi para UMKM Kuliner yang hadir sebagai peserta pelatihan ini. Terdapat tiga manfaat menjadi wirausaha, yaitu (1) memulai satu lapangan kerja untuk diri sendiri; (2) membuka lapangan pekerjaan bagi masyarakat; dan (3) berkontribusi dalam pembangunan ekonomi Indonesia. Pemateri juga menyampaikan bahwa profil wirausaha yang sukses adalah wirausaha yang kerja lebih keras, kerja lebih cerdas, kerja lebih tuntas dan kerja lebih ikhlas. Pada sesi diskusi, pemilik UMKM menyampaikan bahwa mengalami penurunan omzet selama masa pandemi ini. Rekomendasi yang disampaikan oleh pemateri agar UMKM kuliner ini mampu bertahan ditengah pandemi Covid-19 adalah bergabung dengan berbagai komunitas sehingga produk kulinernya semakin dikenal dan meningkatkan konsumen. Pertanyaan lain yang diajukan 
adalah terkait manajemen sumber daya manusia, mengingat jumlah karyawan UMKM relatif sedikit. Pemateri menyarankan untuk berkolaborasi dengan mitra yang dapat bersama-sama mengelola UMKM.

Gambar 1. Paparan Materi How Culinary Business Can Survive During Pandemic

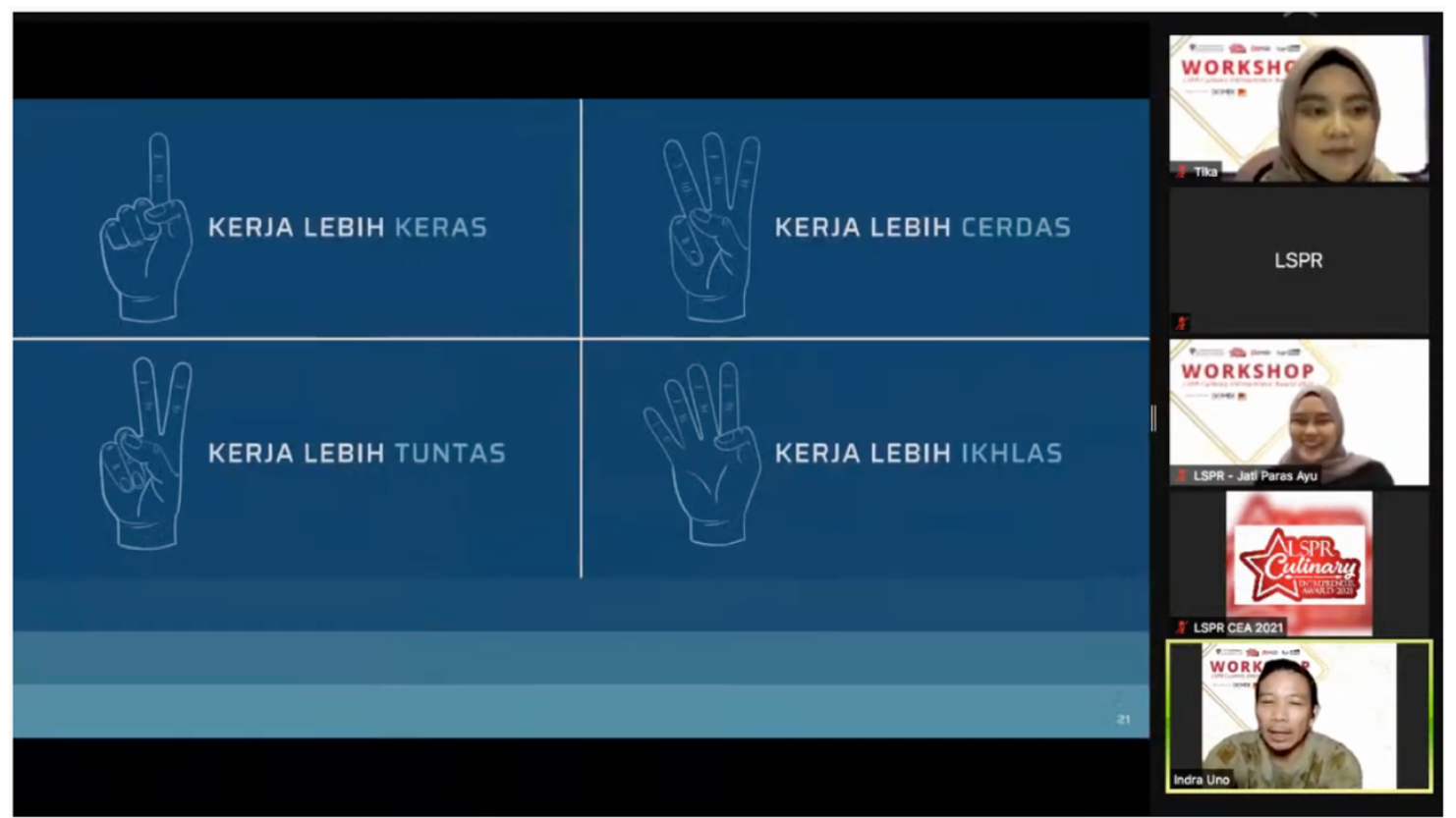

Sumber: Dokumentasi Panitia LSPR Culinary Entrepreneur Award 2021

Pada sesi kedua, disampaikan materi mengenai 'The Role of Social Media for Branding' oleh Chief Editor MIX Marcomm Magazine yaitu Ibu Liz Hendriani. Di awal, pemateri menyampaikan bahwa terdapat perubahan perilaku masyarakat Indonesia yang semakin menunjukkan tingginya penggunaan sosial media sebagai media belanja. Hal ini sesuai dengan hasil survei yang dilakukan oleh We Are Social (Januari 2021), bahwa masyarakat Indonesia rata-rata waktu yang digunakan untuk sosial media adalah 3 jam 14 menit dan 65\% digunakan untuk mencari berbagai informasi terkait merek (brand). Oleh karena itu, penting bagi UMKM untuk menggunakan media sosial sebagai taktik komunikasi pemasaran. Selain itu, disampaikan juga bahwa sejak pandemi Covid-19 terdapat peningkatan penggunaan website, YouTube, Facebook dan berbagai platform digital lainnya sehingga UMKM di Indonesia harus go digital agar selaras dengan perubahan perilaku masyarakat Indonesia. Pemateri juga menyampaikan bahwa konten komunikasi pemasaran yang tepat untuk media sosial adalah video karena lebih menarik dibandingkan hanya mengunggah foto. Konten online yang paling diminati oleh masyarakat Indonesia adalah video dengan persentase $98 \%$ (We Are Social, 2021).

Media sosial merupakan shared media yang dapat berperan sebagai media komunikasi pemasaran bagi usaha bisnis dengan biaya yang relatif terjangkau bagi UMKM. Pemilik UMKM dapat membuat dan mengelola konten serta interaksi dengan konsumen secara mandiri. Pemateri menyampaikan tiga pilar yang dapat menjadi panduan bagi UMKM Kuliner 
dalam berkomunikasi dengan konsumen melalui media sosial. Pertama adalah channel, pilih media sosial yang sesuai dengan pasar sasaran. Jika dominan pasar sasaran yang akan dijangkau oleh UMKM Kuliner adalah generasi muda maka Facebook, Instagram dan Twitter menjadi pilihan yang tepat. Kedua adalah content. Buatlah konten yang menarik dan interaktif seperti video. Ketiga adalah context, yaitu konten yang disampaikan relevan dengan situasi terkini, mengikuti tren, manfaatkan momentum pemasaran seperti hari raya.

\section{Gambar 2. Materi 'The Role of Social Media for Branding'}

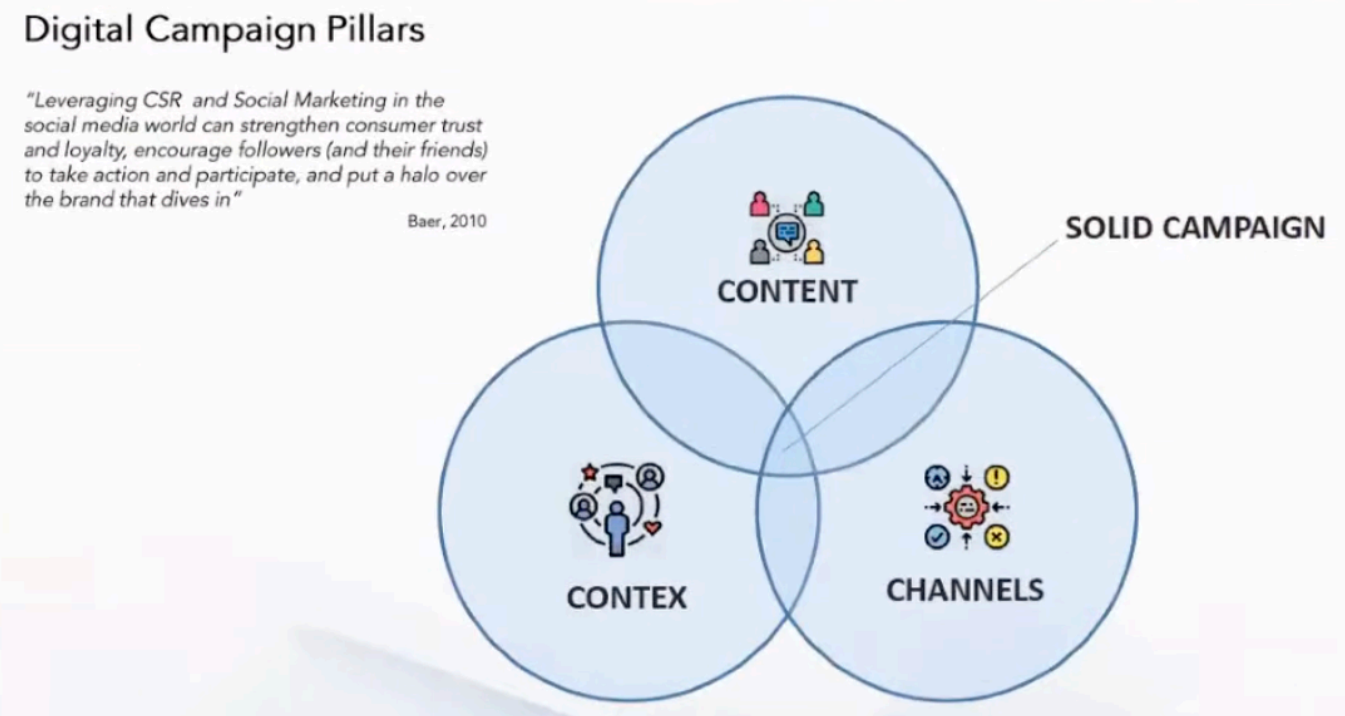

Sumber: Dokumentasi Panitia LSPR Culinary Entrepreneur Award 2021

Pada sesi diskusi, ditanyakan terkait penggunaan digital komunikasi pemasaran yang efektif bagi UMKM kuliner guna meningkatkan omzet pada masa pandemi Covid-19. Tiga hal yang disampaikan sebagai rekomendasi, yaitu (1) gunakan Instagram sebagai media promosi; (2) posting konten setiap hari; dan (3) video merupakan konten yang menarik dan paling banyak ditonton oleh masyarakat digital.

Komunikasi pemasaran melalui sosial mesia telah terbukti memudahkan proses komunikasi dan dapat menjangkau pasar sasaran lebih cepat, tepat, dan luas. Oktaviani \& Rustandi (2018) menyatakan bahwa Instagram merupakan media komunikasi pemasaran yang efektif dan juga biaya yang murah serta jangkauan yang tak terbatas. Komunikasi pemasaran pada Instagram dapat membangun kepercayaan pada konsumen melalui konten berupa testimoni maupun komentar yang positif berdasarkan pengalaman konsumen menggunakan produk. Penelitian yang dilakukan oleh Damayanti (2018) pada UMKM Kuliner Warteg Hipster menunjukkan bahwa konten digital marketing melalui Instagram dapat membangun brand awareness dan mendorong masyarakat untuk melakukan pembelian. Hal ini terbukti dengan meningkatkanya pengunjung dan omzet Warteg Hipster. 
Oleh karena itu, penggunaan media sosial sebagai taktik komunikasi pemasaran menjadi suatu keharusan bagi UMKM. Di era teknologi digital, saat konsumen membutuhkan sesuatu atau ingin membeli sebuah produk, atau ingin menikmati kuliner tertentu, maka langkah pertama konsumen adalah mencari informasi di media sosial. Kondisi ini disebut pull digital marketing yaitu keaktifan calon konsumen dalam mencari informasi mengenai produk atau jasa yang dibutuhkan.

Tabel 1. Kelebihan Media Sosial

\begin{tabular}{|c|c|}
\hline Saluran & Kelebihan \\
\hline Facebook & $\begin{array}{l}\text { Facebook mudah untuk melakukan komunikasi pemasaran } \\
\text { berdasarkan segmentasi konsumen. Hal ini membuat } \\
\text { komunikasi pemasaran yang dilakukan menjadi lebih fokus } \\
\text { dan terarah. Konsumen dapat melakukan interaksi melalui } \\
\text { fitur comments. }\end{array}$ \\
\hline Twitter & $\begin{array}{l}\text { Keunggulannya dapat mendorong interaksi dan diskusi secara } \\
\text { cepat dan jangkauannya luas, namun penggunaan hashtag } \\
\text { dan foto di Twitter relatif terbatas. }\end{array}$ \\
\hline LinkedIn & $\begin{array}{l}\text { Memiliki dampak yang signifikan untuk menjangkau } \\
\text { profesional dan melakukan prospek terhadap Business } \\
\text { to Business (B2B). }\end{array}$ \\
\hline Instagram & $\begin{array}{l}\text { Cara terbaik untuk mempromosikan merek atau produk jika } \\
\text { fokusnya adalah iklan visual. }\end{array}$ \\
\hline WhatsApp & $\begin{array}{l}\text { Mudah untuk digunakan, dapat membuat sebuah grup atau } \\
\text { komunitas online dan jangkauan pasar sasaran yang luas. } \\
\text { Kelemahannya pesan atau respon dapat tidak terbaca dengan } \\
\text { baik serta keterbatasan memori WhatsApp. }\end{array}$ \\
\hline YouTube & $\begin{array}{l}\text { YouTube menjadi media yang potensial untuk melakukan } \\
\text { komunikasi pemasaran berbasis video. Video promosi yang } \\
\text { menarik dan mudah untuk dipahami akan membantu } \\
\text { membangun kredibilitas. }\end{array}$ \\
\hline TikTok & $\begin{array}{l}\text { Berguna untuk kampanye yang menggunakan video. } \\
\text { Pembuatan video dengan TikTok mudah dan praktis. Interaksi } \\
\text { dengan pengunjung dapat terjalin secara langsung dan cepat. }\end{array}$ \\
\hline
\end{tabular}

Sumber: Data Olahan Peneliti (2021)

As'ad \& Alhadid (2014) menyampaikan lima faktor penting dalam penggunaan media sosial dalam pemasaran. (1) Online communities, usaha bisnis dapat menggunakan media sosial untuk membangun komunitas yang memiliki kesamaan minat pada produk atau bisnisnya. Interaksi dalam komunitas melalui diskusi, membagi (sharing) informasi akan bermanfaat 
untuk pengembangan dan kemajuan bisnis serta membangun loyalitas; (2) Interaction, fitur di media sosial memungkinkan terjalinnya interaksi yang besar dengan online communities; (3) Sharing of content, distribusi konten baik dari pihak pelaku bisnis maupun konsumen. Konsumen akan memberikan feedback jika konten yang diunggah terkini dan relevan dengan kondisi yang ada; (4) Accessibility, mengacu pada kemudahan untuk mengakses; dan (5) Credibility. Konten berupa testimoni serta komentar positif dari konsumen dapat membangun kredibilitas suatu usaha bisnis.

Sesi ketiga mengenai 'The Need of Public Relations for Entrepreneur' yang disampaikan oleh Founder dan CEO Institut Komunikasi dan Bisnis LSPR yaitu Ibu Prita Kemal Gani. Reputasi harus dibangun, reputasi harus diciptakan. Public relations dibutuhkan oleh wirausaha untuk membangun reputasi. Masyarakat cenderung membeli produk yang dihasilkan oleh pengusaha yang memiliki reputasi yang baik. Reputasi pemilik atau wirausaha penting karena melekat di produk. Sehingga seorang pebisnis tidak hanya menjual produk atau jasa saja. Namun perlu mengaplikasikan strategi public relations, agar bisnis dapat bertahan lama. Aktivitas public relations menggunakan teknik storytelling, menceritakan bagaimana pengusaha menghasilkan suatu produk, bagaimana produk berkualitas dibuat, apa latar belakang bisnis itu dibuat, seberapa higienis suatu produk. Jika berfokus hanya menghasilkan sales, dan kuantitas yang dijual, hal tersebut hanya sebatas teknik Marketing. Jika suatu brand sudah memiliki reputasi baik, sudah dipercaya oleh stakeholders, serta sudah memiliki loyal customer, itulah hasil dari jangka panjang bahwa strategi Public Relations sudah dijalani dengan baik. Dalam menjalankan usaha, pengusaha atau pebisnis yang sukses harus memberikan solusi dari permasalahan atau menjawab kebutuhan masyarakat.

Pemateri juga menyampaikan bahwa Pierre Bourdieu, filsuf Perancis membagi tahapan Reputasi, Hal yang paling mendasar adalah financial history. Kemampuan dalam kedisiplinan mengatur keuangan sangatlah penting. Menentukan modal, mengatur keuntungan, dan mengatur cash flow perlu dikuasai seorang pengusaha. Financial adalah fondasi dalam menunjang pendirian suatu bisnis. Setelah memiliki kreativitas, keberhasilan mengelola dana, mempertahankan dan menghargai sejarah dari perusahan sangat penting. Pengusaha bukan hanya dapat menjual produknya dalam volume yang banyak, namun pengusaha perlu memastikan bisnisnya konsisten tetap ada dan sukses dari tahun ke tahun, dan kualitas produk tetap baik bahkan pengusaha perlu melakukan inovasi. Berikutnya agar produk standout dan dapat dilirik oleh konsumen adalah memiliki logo yang relevan, packaging produk yang menarik dan fungsional juga dapat menentukan reputasi suatu brand. Tahapan berikutnya, brand suatu produk atau perusahaan dapat mengikuti ajang kompetisi seperti LSPR Culinary Entrepreneur Award 2021 ini agar mendapatkan rekognisi, meningkatkan awareness, serta mendapatkan pengetahuan dan masukan dari para juri untuk mengembangkan bisnis. Dalam mengikuti ajang kompetisi LSPR CEA 2021, pengusaha menyiapkan proposal bisnis, presentasi di hadapan juri dan tanya jawab, tentu memberikan banyak manfaat dan termotivasi menjadi lebih baik lagi. 
Kemampuan mengatur tim juga menentukan keberhasilan suatu brand. Bagaimana seorang pemimpin dapat mengatur pekerjaan, membagi pekerjaan sesuai kemampuan tim, memastikan pekerjaan selesai tepat waktu, menjalankan keselamatan kerja dengan baik, melaksanakan SOP dengan baik. Sehingga tercapailah tujuan yang diinginkan.

Selanjutnya, suatu bisnis penting memperhatikan Investor Relations. Jika produk dan perusahaan memiliki reputasi yang baik, tentu Investor berkenan menanam saham pada suatu brand atau perusahaan. Riset menyatakan bahwa reputasi CEO sebesar $44 \%$ sangat menentukan reputasi suatu perusahaan. Hal ini dikarenakan CEO memiliki peranan sangat penting menentukan irama kerja, mengarahkan perusahaan agar berjalan sesuai visi dan misi, mengarahkan dan memaksimalkan talenta manajemen. Sedangkan 56\% reputasi perusahaan terdiri dari sejarah perusahaan, performa atau kualitas suatu produk atau jasa dari perusahaan tersebut, manajemen profesional dan terlatih.

Oleh karena itu, seorang CEO perlu memiliki personal reputation atau personal branding yang baik. Pemateri memberikan contoh berdasarkan pengalamannya sebagai entrepreneur yaitu ketika beliau mendirikan Sekolah Tinggi Ilmu Komunikasi LSPR maka reputasi yang disampaikan adalah pendiri merupakan tamatan Sekolah Public Relations, seorang Dosen, dan public relations adalah passion beliau. Pemimpin perusahaan atau CEO perlu merelevansi reputasi perusahaan dan reputasi CEO tersebut. Dengan adanya reputasi, membuat CEO lebih dikenal, menginfokan keahlian kita, mengedukasi, dan memberikan manfaat kepada masyarakat luas sesuai kapabilitas CEO. Setelah produk sudah dikenal dan CEO dikenal, reputasi produk dan reputasi CEO harus relevan dan saling mendukung.

Pada tahap evaluasi, pelaku UMKM Kuliner ini mengirimkan proposal yang menjelasakan mengenai inovasi dalam pengembangan produk, desain kemasan atau cara penyajian produk kuliner, strategi pemasaran meliputi segmentation, targeting dan positioning, taktik pemasaran dan motivasi dan pola pikir kewirausahaan. Proposal ini dievaluasi oleh dewan juri yang terdiri dari para pengusaha sukses, praktisi dan akademisi dibidang bisnis. Berdasarkan hasil evaluasi dan penilaian dari dewan juri, maka terpilih 10 UMKM Kuliner yang akan masuk ke tahap presentasi. Masing-masing peserta UMKM Kuliner akan dinilai kemampuan melakukan presentasi yang menarik dan persuasif terkait usaha kulinernya. Promosi dilakukan melalui taktik social media marketing yaitu penggunaan Instagram dan promosi penjualan yang dilakukan di e-commerce serta mengikuti pameran atau bazar.

Evaluasi 10 UMKM Kuliner sebagai berikut: pertama, Randang Abak, UMKM kuliner yang menonjolkan kuliner terkenal dari Padang dengan tagline "Lammaak Banaa". Bumbu dari resep leluhur Minang, bahan berkualitas, harga terjangkau, dikemas secara modern, menarik dan tersedia berbagai ukuran 150 gram dan 250 gram, tersedia pilihan tingkat kepedasan. Bermitra dengan e-commerce seperti Shopee dan Tokopedia. Inovasi pengembangan produk 
Randang Abak dilakukan guna menyiapkan tujuan eksport yaitu dengan mengembangkan berbagai cita rasa dan produk tidak mengandung MSG. Selain itu, Rendang Abak juga melakukan inovasi dalam kemasan yang dibuat secara modern dan aman dengan menggunakan bahan yang tahan panas. Taktik promosi pemasaran yang dilakukan adalah melalui promosi penjualan di marketplace, menggunakan sosial media Instagram dan mengikuti pameran atau bazaar. Dari sisi reputasi, pemilik Randang Abak membangun dengan mengikuti berbagai kompetisi dan secara konsisten mengunggah product review atau testimoni dari konsumen di media sosial.

Kedua, Metime Fresh merupakan UMKM yang menyediakan minuman dengan bahan dasar susu almond dengan tagline 'stay happy, keep healthy'. Produk minuman terdiri dari almond milk dengan dua jenis yaitu Susu Almond Happy dan Susu Almond Healthy, Soya Milk, Trio Syeger, Pakcoy Nanas, Lemon Honey, Black Cincau dan Almond Boost. Kekuatan dari Metime Fresh adalah meyajikan produk minuman yang sehat dan harga terjangkau. Kelemahannya bahan baku yang spesifik dan produk mudah ditiru oleh pesaing. Metime Fresh terus melakukan inovasi produk minuman yang sehat dengan bahan-bahan sayuran dan buah dari Indonesia. Metime Fresh juga telah menggunakan media sosial sebagai taktik promosi. Media sosial yang dipilih adalah Instagram. Selain itu, Metime Fresh menggunakan Google My Business, dan reseller untuk mendukung promosi yang lebih masif. Pemilik Metime Fresh membangun reputasi sebagai produsen minuman susu yang sehat dengan menyajikan berbagai konten di media sosial yang menyampaikan manfaat minuman sehat di media sosial dan mengikuti berbagai kompetisi UMKM.

Ketiga, Pitiks Roast Chicken merupakan UMKM kuliner bergaya chef food yang berkonsep sharing food yang berawal dari garasi rumah. Produk kuliner berbahan utama ayam yang diolah secara sehat karena tidak diolah dengan oven. Produk kuliner yang ditawarkan adalah Pitiks Family Box, Pitiks Leg dan Pitiks Parmigiana. Harga yang ditawarkan berkisar dari Rp $55.000,00$ sampai Rp 198.000,00. Kelemahannya adalah produk kuliner Pitiks Roast Chicken ditawarkan dengan sistem pre-order, area pengiriman yang terbatas sekitar Jabodetabek dan promosi melalui media sosial hanya menggunakan Instagram dan WhatsApp. Rekomendasi yang disampaikan untuk mengembangkan bisnis adalah berkolaborasi dengan mitra guna membangun sistem delivery dan komunikasi pemasaran yang lebih efektif sehingga pemilik Pitiks Roast Chicken yang merupakan koki dapat fokus pada pengembangan produk kuliner. Pemilik Pitiks Roast Chicken membangun reputasi sebagai produsen Chef Food dengan di media sosial dengan menggunggah konten-konten produk Pitiks Roast Chicken yang disajikan secara berkelas.

Keempat, Salaku Cara Enak Makan Salak yang merupakan UMKM Kuliner yang berada di Bekasi ini merupakan produsen olahan salak yang menerapkan sistem zero waste. Berbagai produk olahan Salak disajikan seperti Kerupuk Salak (Kruplak), Bolu Salak, Pie Susu Salak, Brownies Salak (Brownlak) dan berbagai minuman yang berbahan dasar salak seperti Kopi 
Salak (Kojilak). Kekuatannya adalah jenis produk olahan salak bervariasi dari makanan ringan, kue sampai minuman, makanan sehat, zero waste, bermitra dengan GoFood dan GrabFood. Kelemahannya adalah produk olahan berbahan baku salak belum populer dan bahan baku yang spesifik. Salaku perlu melakukan komunikasi pemasaran secara luas dan terus menerus agar masyarakat semakin mengenal produk olahan dari salak. Salaku mempromosikan produknya melalui media online seperti Instagram, Facebook, WhatsApp dan mengikuti berbagai pameran. Salaku sebagai produsen oleh-oleh khas Bekasi sudah mendapat pengakuan oleh Pemerintah Kota Bekasi. Beberapa artikel mengenai Salaku sudah dipublikasikan di berbagai media massa. Salaku kerap mengikuti pameran dan kompetisi untuk membangun reputasi. Oleh karena itu, Salaku telah membangun reputasi dengan sangat baik.

Kelima, Ramen \& Sushi Emperan, UMKM yang menyajikan kuliner Japanese food berkualitas restoran dengan harga emperan. Produk kuliner yang disajikan adalah sushi dan ramen, namun telah disesuaikan dengan cita rasa Indonesia. Kekuatan dari Ramen \& Sushi Emperan adalah harga yang terjangkau, terdapat pilihan tingkat pedas untuk kuah ramen, pasar sasaran semua kalangan, tersedia makan ditempat (dine in) dan telah bermitra dengan GoFood dan GrabFood untuk layanan pesan antar online. Kelemahannya produk mudah ditiru oleh kompetitor. Oleh karena itu, ciptakan ciri khas khusus yang menjadi ikon produk Ramen \& Sushi Emperan. Taktik promosi yang dilakukan adalah melakukan promosi penjualan setiap hari, gratis takoyaki untuk pembelian minimal $\mathrm{Rp} 100.000,00$, pemberian voucher $\mathrm{Rp}$ 25.000,00 untuk pembelian minimal Rp 250.000,00. Selain itu, Ramen \& Sushi Emperan juga menggunakan sosial media marketing khususnya Instagram dan Facebook dalam mengomunikasikan produknya. Ramen \& Sushi Emperan membangun reputasi sebagai ramen dengan kuah terenak di Bekasi. Hal ini menunjukkan bahwa Ramen \& Sushi Emperan fokus pada salah satu elemen pendukung dari produk kuliner yaitu kuah Ramen. Saran perbaikan adalah dapat mencari keunikan dan keunggulan dari produk utama Ramen \& Sushi agar sesuai dengan brand.

Keenam, Kopitia atau Kopi Timur Jakarta, merupakan kedai kopi yang memiliki produk unggulan Kopi Susu Gula Aren. Kopitia menggunakan biji kopi nusantara yaitu Flores dan Lampung. Kekuatan dari Kopitia adalah menggunakan bahan baku kopi yang berkualitas, rasa kopi susu yang creamy dan tidak menimbulkan efek perih pada lambung, harga terjangkau, terdapat pilihan size untuk kemasan botol dan tempat yang strategis. Kopitia juga telah bermitra dengan GoFood, GrabFood, dan Shopee Food. Kelemahan adalah bahan baku yang spesifik sehingga harus menjaga dan mengontrol ketersediaan bahan baku dengan baik. Taktik promosi yang digunakan adalah promosi penjualan seperti diskon dan penggunaan media sosial Instagram. Pemilik Kopitia membangun reputasi melalui konten review produk dan testimoni di media sosial. Untuk mebangun kepercayaan konsumen akan proses produksi yang aman dan bersih maka Kopitia juga mengunggah konten mengenai proses produksi di media sosial. 
Ketujuh, Si Cemplon UMKM Kuliner fokus pada makanan ringan dari kentang seperti Kentang Kriuk Non-MSG Rasa Seafood, Kentang Kriuk Non-MSG Teri Medan. Kekuatan produk kuliner si Cemplon adalah makanan ringan yang sehat, tidak mengandung MSG, menggunakan bahan baku kentang Dieng yang berkualitas, produk ramah lingkungan karena kulit kentang diolah menjadi keripik kulit kentang, kemasan berkelas, harga terjangkau. Taktik komunikasi pemasaran yang dilakukan menggunakan media sosial seperti Instagram, Facebook, YouTube, dan WhatsApp, iklan gratis dan berbayar di e-commerce seperti Tokopedia, Bukalapak, dan Shopee. Selain itu, Si Cemplon juga menggunakan promosi penjualan dengan membagikan tester kepada beberapa toko serta mengikuti berbagai pameran. Untuk konten yang diunggah pada media sosial, Si Cemplon membuat konten yang menyampaikan kelebihan dan manfaat produk kuliner, testimoni dari pelanggan, video proses produksi serta video endorse yang dilakukan oleh public figure. Si Cemplon membangun reputasi sebagai produk kuliner yang "Enak tanpa MSG" dengan fokus pada konten di media sosial. Si Cemplon berhasil memanfaatkan platform digital sehingga produk kulinernya di kenal di pasar ASEAN seperti Malaysia dan Singapura.

Kedelapan, Le Difia Cake and Bakery menyediakan produk roti dan kue yang enak dan sehat untuk memenuhi kebutuhan masyarakat sehari-hari dengan harga yang terjangkau.Kekuatan dari Le Difia Cake and Bakery adalah menggunakan bahan baku yang berkualitas, pilihan rasa yang beragam, harga yang terjangkau, layanan antar gratis untuk lokasi Bekasi dan telah bermitra dengan supermarket HARI-HARI dan supermarket Naga Swalayan untuk dapat memasarkan produk kulinernya di area Jakarta dan Bekasi. Kelemahan, produk mudah ditiru oleh pesaing, maka Le Difia Cake and Bakery harus terus melakukan inovasi produk dan memiliki ciri khas produk roti dan kue. Promosi dilakukan menggunakan media sosial Instagram, Facebook dan WhatsApp, website, dan Google My Business. Pemilik Le Difia Caje and Bakery membangun reputasi dengan mengikuti secara aktif berbagai komunitas dan organisasi khususnya dibidang kewirausahaan. Reputasi juga dibangun melalui platform digital baik melalui media sosial dan website dengan menyampaikan konten seperti proses produksi pembuatan roti dan kue serta keunggulan dan manfaatnya. Le Difia Caje and Bakery juga berpartisipasi dalam berbagai kegiatan (event) sebagai mitra sponsorship.

Kesembilan, Bakmi Kodut atau Bakmi Kedoya Utara adalah UMKM Kuliner merupakan pelopor Bakmi fusion oriental Indonesia yang modern. Bakmi Kodut menyajikan bakmi memadukan cita rasa nusantara dan oriental. Kekuatan Bakmi Kodut adalah harga terjangkau, pilihan topping beragam, tersedia dine in dan telah bermitra dengan GoFood dan GrabFood untuk layanan pesan antar online. Taktik komunikasi pemasaran fokus pada digital marketing dengan penggunaan website, Google Ads, Instagram, Facebook, TikTok, WhatsApp, dan YouTube. Selain itu, Bakmi Kodut juga menggunakan Food Blogger dan Youtuber untuk memromosikan produknya. 
Kesepuluh, Pondok Ngopi (Pongo) yang mengusung tema Old Fashioned Coffee Shop menyediakan kopi rempah dengan harga yang terjangkau. Kekuatannya adalah kedai kopi yang nyaman dengan interior classic pop art. Positioning Pongo adalah rumah kedua dimana pelanggan dianggap seperti anggota keluarga, dilayani dengan ramah dan menjadi meeting point yang nyaman dan menyenangkan. Pongo fokus pada social media marketing yaitu Instagram dan Facebook dalam mempromosikan kedai kopi. Reputasi Pongo sebagai rumah kedua dibangun dengan menjalin keakraban antara pemilik, staf dengan para pengunjung Pongo.

Para UMKM Kuliner ini sebagian besar telah menggunakan media sosial sebagai taktik komunikasi pemasaran. Dominan memilih menggunakan Instagram sebagai media sosial utama dalam memkomunikasikan produknya. Oleh karena itu, pelaku UMKM Kuliner ini perlu memperhatikan kualitas informasi yang disampaikan melalui media Instagram. Informasi yang disampaikan akurat dan senantiasa diperbaharui, informasi yang disampaikan memberikan manfaat dan sesuai dengan kebutuhan follower (Agustine \& Prasetyawati, 2020).

\section{SIMPULAN}

Pelatihan Culinary Entrepreneur untuk UMKM yang berada di Jabodetabek merupakan bentuk dukungan dan pemberdayaan agar UMKM Kuliner mampu bertahan dalam kondisi pandemi ini. Bimbingan yang dilakukan melalui pelatihan khususnya terkait penggunaan sosial media sebagai taktik komunikasi pemasaran diharapkan dapat membantu UMKM kuliner untuk memilih media sosial yang tepat dan membuat konten yang sesuai dengan pasar sasaran dan membantu membangun brand awareness.

Paparan pemateri terkait strategi digital marketing, pembangunan reputasi melalui public relations dan pola pikir wirausaha untuk meningkatkan motivasi wirausaha bagi para UMKM meningkatkan pengetahuan dan ketrampilan berbisnis

Berdasarkan hasil evaluasi, para pelaku UMKM Kuliner beberapa hal yang perlu diperbaiki adalah keunikan dari produk kuliner yang ditawarkan agar tidak mudah ditiru oleh kompetitor. Selain itu, perlu dikembangkan adalah kualitas konten yang disampaikan dalam media sosial agar menonjolkan konten-konten yang bermanfaat bagi konsumen, visual dan pilihan kata yang menarik dan bervariasi. Para pelaku UMKM Kuliner membangun reputasi melalui media sosial, mengikuti pameran dan kompetisi. 


\section{DAFTAR PUSTAKA}

Agustine, M. \& Prasetyawati, Y.R. (2020). Pengaruh kualitas informasi Instagram dan electronic word of mouth terhadap citra dapurfit. Profesi Humas, 5(1), 82-97. https://doi.org/10.24198/prh.v5i1.23966

As'ad H. A. R. \& Alhadid, A. Y. (2014). The Impact of Social Media Marketing on Brand Equity: An Empirical Study on Mobile Service Providers in Jordan. Review of Integrative Business and Economics Research,3(1), 316-329.

Catriana, E. (2020). Ini Sejumlah Faktor yang Menyebabkan Bisnis UMKM Merosot Selama Pandemi. Kompas.com. https://money.kompas.com/read/2020/08/03/170220126/inisejumlah-faktor-yang-menyebabkan-bisnis-umkm-merosot-selama-pandemi

Damayanti, E. (2018). Konten Digital Marketing Melalui Instagram Warteg Hipster Dalam Upaya Membangun Brand Awareness. eProceedings of Management, 5(1), 1333-1340.

Hardilawati, W. L. (2020). Strategi Bertahan UMKM di Tengah Pandemi Covid-19. Jurnal Akuntansi \& Ekonomika, 10(1), 89-98. https://doi.org/10.37859/jae.v10i1.1934

Oktaviani, F. \& Rustandi, D. (2018). Implementasi Digital Marketing Dalam Membangun Brand Awareness. PRofesi Humas, 3(1), 1-20. https://doi.org/10.24198/prh.v3i1.15878

Rosita, R. (2020). Pengaruh Pandemi Covid-19 Terhadap UMKM di Indonesia. Jurnal Lentera Bisnis, 9(2), 109 - 120. https://doi.org/10.34127/jrlab.v9i2.380

We Are Social. (2021, Februari 11). Digital 2021: Indonesia. DataReportal. https://datareportal.com/reports/digital-2021-indonesia 